\title{
Fatores de satisfação preconizado por consumidores em serviços de supermercados
}

Os supermercados servem de elo na cadeia entre produtores e seus consumidores finais. Todavia, o consumidor possui uma visão do que seria valor para si, cabendo aos supermercados compreender esse valor, a partir da identificação dos fatores de qualidade que preconizam a satisfação dos clientes e o aumento de desempenho. Sendo, portanto, o objetivo deste estudo o de identificar os principais fatores de satisfação preconizado pelos consumidores em serviços de supermercados. 0 método empregado caracteriza-se por uma pesquisa descritiva envolvendo uma survey com 240 clientes de supermercados do extremo norte gaúcho. Como resultado obteve-se oito fatores que proporcionam valor (benefícios) para a clientela: atendimento, variedades, promoções, produtos, ambiente, preços, acessibilidade e localização. Além da contribuição para gestão mercadológica do setor supermercadista e ao bem estar social da população onde o estudo foi desenvolvido, o trabalho também proporciona implicações acadêmicas e científicas, ao ampliar o estudo dos fatores que influenciam na satisfação dos consumidores em supermercados.

Palavras-chave: Serviços; Supermercados; Consumidor; Fatores de Satisfação.

\section{Factors influencing consumer satisfaction related to supermarket services}

\begin{abstract}
Supermarkets are a link between producers and end consumers. Nevertheless, consumers have an opinion about what would be value for them, and supermarkets have to understand what this value is, and then to develop more sophisticated position strategies aiming consumers satisfaction and to increase supermarket performance. The aim of this study is to identify the main factors that influence consumer satisfaction related to supermarket services. The methodology employed was characterized by a descriptive research involving a survey of 240 supermarket customers in the extreme north of Rio Grande do Sul. The results showed eight factors that provide value (benefits) for the customers: customer service, variety, sales, products, environment, prices, accessibility and location. Besides its marketing contribution to the supermarket business and to the wellbeing of the population where it was conducted, this study also has academic and scientific implications because it widens the study of factors that influence consumer satisfaction in supermarkets.
\end{abstract}

Keywords: Service; Supermarkets; Consumer; Satisfaction Factors.

Topic: Marketing e Estratégias Mercadológicas

Reviewed anonymously in the process of blind peer.
Received: 09/01/2021

Approved: 21/03/2021
Eliziane Studzinski id

Universidade de Santa Cruz do Sul, Brasil http://lattes.cnpq.br/3138358828014536 http://orcid.org/0000-0002-1211-3868 elizianestudzinski@yahoo.com.br

Carlos Alberto Mello Moyano (iD)

Universidade de Santa Cruz do Sul, Brasil http://lattes.cnpq.br/2563531377091462

http://orcid.org/0000-0002-9923-3829 carlos@unisc.br

\section{Derli Luís Angnes (ic}

Universidade de Santa Cruz do Sul, Brasil http://lattes.cnpq.br/8252660541407330 http://orcid.org/0000-0002-3774-7656 derli.angnes@gmail.com
Referencing this:

STUDZINSKI, E.; MOYANO, C. A. M.; ANGNES, D. L.. Fatores de satisfação preconizado por consumidores em serviços de supermercados. Revista Brasileira de Administração Científica, v.12, n.1, p.65-82, 2021. DOI: http://doi.org/10.6008/CBPC2179684X.2021.001.0006 


\section{INTRODUÇÃO}

O autosserviço representa o segmento supermercadista como importante membro do canal varejista e da cadeia de suprimentos, com uma ampla variedade de itens, onde o cliente se dispõe a escolher o produto sem a ajuda de um funcionário, ocupando uma importante posição no setor de varejo, com uma participação de 5,2\% do PIB nacional. Os supermercados são o elo da cadeia entre produtores e seus consumidores finais. Proporcionam a sociedade, sobretudo aos consumidores e a economia comercial: empregos, capital, tecnologia, alta produção, inovação em produtos e abertura de filiais em locais distantes.

A venda dos produtos ofertados em supermercados é direcionada para consumidores finais que buscam produtos/serviços de qualidade, visando atender suas necessidades, desejos e a satisfação a partir do consumo de itens em sua maioria de necessidade básica à população. A satisfação acaba sendo um indicador importante nas relações comerciais em supermercados, caracterizada como o resultado da experiência do desempenho do produto/serviço em relação as expectativas do cliente. Dessa forma, a satisfação é a reação emocional à diferença entre que os clientes antecipam obter e o que eles realmente recebem. Portanto, a satisfação é um resultado positivo na avaliação da alternativa escolhida (ANGELOVA et al., 2011).

Para uma empresa atuar no estilo de vida de seus clientes, exige dela um grande esforço deliberado e consciente de incorporar a orientação para o mercado com a estratégia organizacional apropriada. Portanto, requer um conjunto diferente de habilidades e competências do que as empregadas pela concorrência com atributos funcionais. Deste modo, somente empresas que realmente atingirem um alto grau de competência em estabelecer uma relação verdadeira e de real valor com o cliente, serão bemsucedidas nesta estratégia (CHERNEV et al., 2011).

Cabe, portanto, aos supermercados a estratégia de promover a satisfação da sua clientela, a partir de produtos e serviços que atendam às necessidades e os desejos do seu público alvo com valor. Este entendimento sobre o valor para o cliente permitirá, em última análise, a satisfação dos clientes e o aumento do desempenho do supermercadista (CHAMIE et al., 2015). No entanto, a compreensão dos fatores que promovem valor ao cliente não é totalmente compreensível, é onde surge o problema de pesquisa em identificar quais fatores proporcionam maior satisfação ao consumidor com os serviços de supermercados. Sendo, portanto, o objetivo deste estudo o de identificar os principais fatores de satisfação preconizado pelos consumidores em serviços de supermercados.

Por motivos de conveniência e limitações de tempo e orçamento, a pesquisa foi restrita à consumidores de supermercados localizados na Região do Extremo Norte do Rio Grande do Sul, a partir de uma amostra não probabilística com 240 clientes entre homens e mulheres que compraram em um período de 30 dias em algum dos supermercados da região.

Este trabalho por meio da sua pesquisa trará contribuições relevantes para ampliação do entendimento dos fatores e suas variáveis que impactam diretamente na satisfação do consumidor em serviços de supermercados, sobretudo para a região onde o trabalho foi realizado e que ainda não possui 
publicações sobre o tema, além disso, são incipientes os estudos desenvolvidos acerca dos fatores que promovem a satisfação com os serviços em supermercados. Os trabalhos publicados estão mais direcionados a qualidade dos serviços. Apenas poucas publicações abordam a satisfação dos consumidores com os serviços em supermercados (KONČAR et al., 2015; CLARKE et al., 2012; GALLON et al., 2008). Tendo, portanto, este artigo uma relevância de ordem acadêmica e também gerencial, pois complementa e acrescenta informações para compreensão no comportamento da satisfação do consumidor brasileiro com supermercados a partir dos resultados obtidos com a pesquisa empírica deste estudo.

Concluído este introito, segue uma breve revisão teórica do setor supermercadista e da satisfação do consumidor com supermercados. Na sequência, são apresentados os procedimentos metodológicos da pesquisa, análise dos resultados obtidos, as considerações finais do estudo e a lista de referências de fontes científicas que embasam este estudo.

\section{REVISÃO TEÓRICA}

\section{Setor supermercadista brasileiro}

Dentre os diversos setores da economia, o varejista na qual os supermercados fazem parte, é comumente compreendido como a área de disponibilização e venda de mercadorias para o cliente, que por sua vez é uma compreensão simplista, já que no varejo existem trocas de valores, trocas subjetivas e objetivas, que colocam o cliente na posição de receber produto/serviço ou conveniência, e por outro lado coloca a empresa como recebedora do tempo, do dinheiro e da disposição ao cliente (CHAMIE et al., 2015). Segundo a Associação Brasileira de Supermercados, os supermercados são empresas de varejo e autosserviço. O termo autosserviço (self-service), sistema no qual o cliente escolhe o produto sem ajuda de um funcionário, foi utilizada pela primeira vez em 1912 por comerciantes do estado da Califórnia (Estados Unidos), para definir a forma de operação de suas lojas. Já a denominação de supermercado (supermarket), surgiu da influência do cinema, no qual a palavra 'super' era empregada com frequência para algo grandioso.

No entanto, o supermercado no formato que conhecemos surgiu nos Estados Unidos (EUA), na década de 1930, período que mostrou sua força e importância para o sistema de distribuição de alimentos em todo o país (ASCAR, 2018). Sendo que no Brasil os supermercados surgiram na Década de 50, com a efetuação do sistema de autosserviço, ocupando uma posição de destaque no ramo de varejo, formando um importante segmento de distribuição com o conceito de evolução e modernização envolvendo atividades comerciais de venda de mercadorias para consumo próprio.

O supermercado é considerado como parte de um canal de distribuição, no qual o autosserviço e a venda de diferentes produtos são características próprias deste setor, definidos por Silveira et al. (1997) como "um varejo generalista que revende ao consumidor final uma ampla variedade de produtos, dispostos de forma departamental no sistema de autosserviço". Desta forma, os públicos dessas lojas são de todas as classes que adquirem produtos alimentícios indispensáveis para o dia a dia de todos. Estas lojas oferecem uma variedade de produtos para atender todas as demandas dos clientes. Os supermercados representam a 
cadeia varejista, isto é, atuam como intermediários entre um produto/serviço e o consumidor final. Pride et al. (2010), definem supermercados como ambientes de autosserviço que ofertam uma linha completa de produtos alimentícios e alguns produtos não-alimentícios. No Brasil, o art. 4ํ inciso XVIII da lei 5991 (BRASIL, 1973), define supermercado como um estabelecimento que comercializa, mediante autosserviço, uma diversidade de mercadorias, sendo em especial produtos alimentícios em geral e produtos de higiene e limpeza.

Os supermercados apresentam uma estrutura grande e complexa sob o ponto de vista de negócios, pois envolve muitos componentes, como uma série de clientes agrupados em várias áreas; uma cadeia de lojas de varejo; vários sistemas de transporte; um conjunto de centros de distribuição de armazém e uma variedade de fornecedores de produtos sob contrato (STEENEKEN et al., 2012).

No Brasil, o setor supermercadista passou por profundas transformações nos últimos anos, tornando-se cada vez mais competitivo e especializado e vem formulando um novo conjunto de estratégias competitivas, que não estão apenas voltadas para custos e preços, e sim de aumentar sua abrangência regional, disseminando lojas especializadas e aumentando a presença de grupos e redes de cooperação em nível nacional.

Estima-se que o Brasil tenha 89,6 mil lojas de supermercados no sistema de autosserviço, sendo estes de pequeno, médio e grande porte. O setor supermercadista brasileiro em 2018 alcançou um faturamento de $\mathrm{R} \$ 355,7$ bilhões, com 1,85 milhões de funcionários diretos e possui os maiores distribuidores de alimentos, bebidas e produtos de limpeza, higiene e beleza do país. A Tabela 1 apresenta detalhadamente os dados consolidados do setor entre 2010 a 2018, com indicadores do número de lojas, faturamento bruto anual em bilhões de Reais, número de empregos diretos, área de vendas em mil metros quadrados e o número de check-outs, chamados terminal de finalização da compra.

Tabela 1: Dados do setor supermercadista brasileiro de 2010 a 2018.

\begin{tabular}{llllllllll}
\hline Indicadores & $\mathbf{2 0 1 0}$ & $\mathbf{2 0 1 1}$ & $\mathbf{2 0 1 2}$ & $\mathbf{2 0 1 3}$ & $\mathbf{2 0 1 4}$ & $\mathbf{2 0 1 5}$ & $\mathbf{2 0 1 6}$ & $\mathbf{2 0 1 7}$ & $\mathbf{2 0 1 8}$ \\
\hline № de lojas & 81.128 & 82.010 & 83.572 & 83.914 & 83.581 & 88.564 & 89.000 & 89.368 & 89.673 \\
Faturamento anual (R\$ Bilhões) & 201,6 & 224,3 & 242,9 & 272,2 & 294,2 & 316,2 & 338,7 & 353,2 & 355,7 \\
№ de empregos diretos (Milhões) & 1,51 & 1,59 & 1,66 & 1,75 & 1,84 & 1,80 & 1,80 & 1,82 & 1,85 \\
Área de vendas (Milhões de m²) & 19,7 & 20,6 & 21,0 & 21,1 & 21,3 & 21,6 & 21,7 & 21,9 & 22,2 \\
№ de check-outs (Mil) & 199,4 & 206,6 & 210,2 & 215,9 & 221,7 & 222,8 & 225,0 & 223,7 & 227,6 \\
\hline
\end{tabular}

Os dados apresentados pela tabela acima resumem e indicam o crescimento anualmente do setor, sobretudo se comparados aos números de 2018 em relação a 2010, números que contribuem para o desenvolvimento econômico e social do país.

Os formatos de loja de autosserviço se diferenciam por características quanto ao público-alvo, pelo número de lojas, área de vendas, número de check- outs e número de itens. A Tabela 2 relaciona os diversos tipos/formatos de loja existentes nesse segmento.

Em decorrência das crises nos últimos anos, os consumidores brasileiros se adaptaram à nova realidade econômica do país, mudaram hábitos e levaram o varejo alimentar a mudar também. Um dos traços marcantes desse período, e que refletiu claramente a partir de 2015 , foi a busca por encontrar meios para que, com menos renda, o brasileiro preservasse o consumo de itens de maior valor agregado, pela troca 
da marca e pela redução da quantidade comprada. Como resultado dessa e de outras mudanças no consumo, houve alteração do peso das seções e no faturamento dos supermercados, do perfil dos produtos mais demandados e dos meios de pagamentos utilizados pelos clientes. A busca por marcas mais acessíveis, elevou o desempenho das marcas próprias. A concorrência continuou a crescer em decorrência da relevância do setor para a subsistência, acirrando a busca por qualidade e por maior satisfação do consumidor como forma de manutenção dos negócios frente a concorrência.

Tabela 2: Características dos principais formatos de loja no Brasil.

\begin{tabular}{llll}
\hline Tipo de loja existentes & Área média de vendas $\left(\mathbf{m}^{\mathbf{2}}\right)$ & $\begin{array}{l}\text { No médio de check-ups } \\
\text { por loja }\end{array}$ & $\begin{array}{l}\text { No médio de itens } \\
\text { por loja }\end{array}$ \\
\hline Conveniência & 81 & 1 & 3.365 \\
Loja vizinhança & 426 & 3 & 8.303 \\
Supermercado & 1.556 & 10 & 16.052 \\
Hiper/supercenter & 3.968 & 23 & 27.403 \\
Atacado de autosserviço/clubes & 3.459 & 12 & 7.416 \\
\hline
\end{tabular}

\section{Satisfação do consumidor com supermercados}

A satisfação do cliente é um elemento essencial e um dos objetivos da atividade de marketing, pois é de suma importância ao cumprimento das necessidades e desejos, sendo identificada como um fator que afeta a taxa de retenção da clientela (JIN et al., 2012).

Os primeiros estudos relacionados a satisfação do consumidor/cliente são da década de 1960 . Segundo Czepiel et al. (1974), a satisfação é uma avaliação subjetiva do consumidor em relação ao grau de contentamento em relação a compra ou consumo na aquisição de um produto/serviço fornecido. Os estudos com a satisfação do cliente se intensificaram no Brasil na década de 90 , com à abertura da economia, e do desenvolvimento de mercados mais competitivos, sendo a década marcada por uma grande diversidade de serviços, competindo no mercado em mudança gradual em direção a uma economia mais aberta e diversificada, tornando a dinâmica da competição crescente.

A palavra satisfação provém dos termos em latim satis, que quer dizer suficiente, e facere, que quer dizer fazer, portanto a palavra satisfação deriva de fazer o suficiente. A busca pela satisfação do cliente é algo importante aos prestadores de serviços, pois o produto/serviço quando não atinge o resultado esperado causa insatisfação aos clientes, já o contrário, quando o resultado alcança o esperado ou até mesmo supera as expectativas dos clientes, consegue-se o objetivo de não apenas atender, mas de encontrá-lo, por isso, é necessário que empresas busquem ao máximo satisfazer seus clientes (OLIVEIRA et al., 2015).

A satisfação resulta de um processo de comparação entre expectativas e desempenho de atributos relevantes. Também é tida como uma experiência emocional dos consumidores ao se sentirem bem consigo ao apreciar alguma experiência positiva (KUNZ et al., 2011). Portanto, a satisfação é essencialmente conceituada como resultante da comparação do desempenho real em relação as expectativas dos clientes. Essa desconfirmação (positiva ou negativa) leva a satisfação ou insatisfação (LEMON et al., 2016). As expectativas são centrais nos processos de satisfação, aumentando ou diminuindo a relação da satisfação (MANTOVANI et al., 2013).

O paradigma da desconformidade concebe a satisfação e a insatisfação como resultado da 
comparação entre expectativas anteriores à compra ou consumo e o desempenho percebido pelo consumidor, afirmando que as necessidades e as motivações pessoais são antecedentes da expectativa em relação ao serviço, isto é, quando o desempenho se mostra superior às expectativas formadas anteriormente, surge a desconformidade positiva e, consequentemente, a satisfação. Sendo que quando o resultado se mostra inferior ao esperado, ocorre a desconformidade negativa, chamada de insatisfação (MUNIZ et al., 2014). A satisfação é um recurso intangível atingido pelo desempenho das expectativas dos clientes, uma consequência de experiência do cliente através do encontro com o serviço (MAHFOOZ, 2014).

Consequentemente admite-se que a satisfação é aquilo que está ligado à qualidade do serviço prestado. Só haverá satisfação do cliente se ele perceber que a empresa se empenhou de fato em descobrir o que ele necessitava e the entregou o produto adequado (YEVDOKYMENKO, 2013). Para Sallam (2016), a satisfação é o comportamento dos clientes em relação a um produto/serviço após o uso. Já Sharma (2014), expõe que a confiabilidade, receptividade, segurança e empatia significativamente às atitudes dos clientes influenciam positivamente em termos de satisfação e fidelidade.

Outrossim, a satisfação do cliente é definida como a avaliação total da performance baseada em todas as experiências (positivas e negativas) anteriores com a empresa (JONES et al., 2000). Pizam et al. (1999), definem a satisfação dos clientes como o sentimento de bem-estar e prazer que resulta da obtenção daquilo que se espera de um produto/serviço. Para Day (1984), a satisfação dos clientes é definida como um julgamento de avaliação de compra relativo à decisão de compra. Kotler et al. (2012) a definem como sensação de prazer ou decepção resultante da comparação do desempenho percebido (ou resultado) de um produto em relação as expectativas. Já Hansemark et al. (2004), ressaltam que a satisfação do cliente é o sentimento ou a atitude dos clientes em relação a um produto/serviço depois de ter sido usado.

Há, portanto, dois tipos de definições sobre a satisfação: a primeira que considera a satisfação como resultado de uma experiência de consumo. E a segunda que mostra a satisfação como perspectiva da experiência de consumo em sua totalidade e salienta as perspectivas de processos perceptuais, avaliativos e psicológicos como geradores da satisfação do consumidor (REIANU, 2014).

É necessário reconhecer que a satisfação do cliente é um instrumento de diferenciação entre as organizações, sendo o estado psicológico que resulta no processo de compra e consumo. Neste sentido, a satisfação ocorre, quando o consumidor de um produto/serviço compara o que é recebido com o que é esperado na utilização de um produto/serviço (KHAN et al., 2014).

Em supermercados a satisfação do cliente pode ser analisada em três estágios: no primeiro estágio o consumidor forma uma expectativa em relação à loja em si, e em relação ao serviço que irá receber (composto supermercadista). No segundo estágio, ocorre a formação da satisfação em relação ao processo de consumo (experiência de consumo), relativo aos produtos e serviços adquiridos, influenciados também pela satisfação relativa à experiência de compra. Após, é formada uma avaliação global da satisfação, relativa ao processo de suporte dado pela loja e ao consumo dos produtos em si. Portanto, a satisfação global é uma combinação da satisfação em relação à experiência de compra e da satisfação em relação à experiência de consumo dos produtos adquiridos (NEUBUSER et al., 2004). 
Acerca das pesquisas de satisfação com supermercados, a partir de uma busca no Portal Web of Science (WOS), revelou como resultado considerando as palavras chaves: satisfaction supermarket, o resultado de cinco artigos científicos publicados entre os anos de 2000 a 2018, sendo apenas três de acesso gratuito (KONČAR et al., 2015; CLARKE et al., 2012; GALLON et al., 2008). Em outros mecanismos de busca também se identificou poucos resultados relacionados às palavras-chave: satisfação em supermercados, o que evidencia poucas pesquisas publicadas relacionadas ao tema, sobretudo no Brasil. De modo geral, as pesquisas sobre supermercados estão mais direcionadas a qualidade e não tanto ao seu consequente que é a satisfação do cliente.

Dos três artigos identificados de acesso público, o de Končar et al. (2015), aborda a satisfação no trabalho em supermercados nos países das Balcãs Ocidentais, a partir da identificação e teste de hipóteses de indicadores de satisfação no trabalho. Em outro artigo, de Clarke et al. (2012), os autores realizaram um estudo acerca da satisfação do consumidor em supermercados no Reino Unido. No Brasil, Gallon et al. (2008), desenvolveram um estudo de avaliação da importância dos atributos e da satisfação dos clientes de supermercados no Médio Vale do Itajaí em Santa Catarina. Destaca-se que nenhum trabalho foi identificado e publicado sobre os fatores que promovem a satisfação com supermercados no Rio Grande do Sul, onde este estudo foi realizado.

A partir da revisão teórica acerca da satisfação do consumidor, fica nítido a compreensão que a qualidade com os fatores que impactam na qualidade do serviço/produto influencia na satisfação e leva a uma maior retenção e lealdade dos clientes em serviços. É importante compreender que a satisfação do cliente é essencial para o sucesso dos negócios e um dos tópicos mais pesquisados em marketing. Sendo de grande valia em termos de desempenho econômico para organizações, incluindo os supermercados. A satisfação também influencia na intenção de compra do consumidor, proporcionando um comportamento de compra repetida. Os comerciantes consideram a melhoria da satisfação do cliente como sendo a estratégia principal para ganhar lealdade, aumentando o valor vitalício do cliente para empresa (PAPPU et al., 2006).

Portanto, a satisfação do cliente é fator determinante de sucesso e dos lucros em uma organização. Quando uma empresa ganha alta lealdade do cliente leva a alta retenção de clientes e os resultados dos negócios tendem a seguir um aumento. Assim, satisfazer os clientes e ganhar lealdade é primordial às organizações (KUMARADEEPAN et al., 2017). Por fim, é importante destacar que a satisfação do cliente tem um impacto positivo na rentabilidade de uma organização, clientes satisfeitos formam a base para o sucesso do negócio, do mesmo modo que a satisfação do cliente leva a recompra (ANGELOVA et al., 2011). Para satisfazer o cliente é imprescindível que se identifique os principais fatores de satisfação preconizados pelos consumidores em relação aos serviços prestados pelos supermercados.

\section{METODOLOGIA}

A pesquisa caracteriza-se como sendo descritiva, recomendada para situações na qual busca-se respostas a questões específicas de estudo (COOPER et al., 2011). O procedimento adotado foi a Survey, a 
partir de um questionário estruturado e com as escalas de diferencial semântico de sete pontos, aplicado para uma amostra não probabilística com 240 clientes de supermercados situados na Região do Extremo Norte do Estado do Rio Grande do Sul.

Ao avaliar o desempenho de um produto/serviço, o cliente geralmente analisa seus principais atributos. A mensuração do nível de satisfação dos clientes serve como uma medida de verificação do desempenho global em relação às expectativas dos clientes (MUNIZ et al., 2014). Desta forma, a medição da satisfação do cliente é utilizada no mercado por organizações privadas, a fim de influenciar a lealdade do cliente, sabendo que o cliente satisfeito vai ter uma maior probabilidade de recompra do mesmo produto ou serviço (REIANU, 2014). Para tanto, é fundamental identificar inicialmente os principais atributos salientes pelos clientes para após analisar os fatores de satisfação que motivam consumidores a frequentar e escolher os supermercados. Na sequência serão apresentadas as etapas da pesquisa que permitirão atingir ao objetivo proposto por este estudo.

Caracterização da amostra: A amostra do estudo foi composta por clientes de supermercados da Região do Extremo Norte do Rio Grande do Sul, que adquiriram serviços/produtos em um período de 30 dias em algum dos supermercados desta região. A amostra utilizada para efetuar o levantamento dos dados da pesquisa descritiva foi por conveniência e amostragem não-probabilística, com 240 clientes de supermercados selecionados entre homens e mulheres que residem na região do Extremo Norte do Estado do Rio Grande do Sul. Sendo o número mais que o suficiente, considerando que a recomendação de Hair Junior et al. (2014), para analisar fatores estatisticamente deve ser de 100 ou mais casos. A amostragem por conveniência tem como vantagem ser menos dispendiosa e consumir menos tempo. Porém, pode ser tendenciosa na seleção e não ser representativa da população (MALHOTRA, 2012), razão pela qual se utilizou diversos pontos de coleta em diversas cidades da região, buscando maior representatividade.

Coleta de dados: Para Enders et al. (1983), o procedimento da coleta de dados permite ao indivíduo fornecer uma listagem de características de suma importância para ele, sendo que o mesmo diferencia e avalia elementos de um conjunto finito, para um motivo específico.

A coleta de dados se deu a partir da aplicação de um questionário estruturado visando obter os resultados da pesquisa descritiva do estudo, contendo variáveis que foram obtidas a partir de uma pesquisa exploratória qualitativa por entrevista prévia com aproximadamente 24 clientes de supermercados da mesma região, o que permitiu identificar os atributos declarados pelos consumidores como aqueles que mais impactam na qualidade dos serviços de supermercados a partir do público-alvo da pesquisa (Variáveis listadas na Tabela 3). Com a identificação das variáveis (atributos de qualidade em supermercados), foi possível elaborar o questionário empregado na pesquisa contendo 38 questões, a partir de uma escala de avaliação por diferencial semântico de sete pontos, cujos extremos da escala vão do (1) Totalmente Insatisfeito ao (7) Totalmente Satisfeito para cada uma das variáveis.

A utilização do questionário é uma técnica estruturada para a coleta de dados que consiste em uma série de perguntas, escritas ou orais, que um entrevistado deve responder. Qualquer questionário tem três objetivos específicos. Em primeiro lugar, deve transformar a informação desejada em um conjunto de 
perguntas específicas que os entrevistados tenham condições de responder. Em segundo lugar, um questionário precisa motivar e incentivar o entrevistado a se deixar envolver pelo assunto, cooperando e completando a entrevista. Em terceiro lugar, um questionário deve sempre minimizar o erro na resposta (MALHOTRA, 2012).

O questionário adotado na pesquisa possui alternativas de respostas fixas. Este tipo de questionário exige que o pesquisado faça a sua escolha em um conjunto predeterminado de respostas, a partir de escalas do tipo Diferencial Semântico, as quais são equilibradas de maneira a ter um número igual de categorias de concordância e de discordância. Todas as categorias de escala são formuladas para reduzir a ambiguidade e a opção "nenhuma opção" não é oferecida, pois os indivíduos entrevistados devem ser capazes de expressar uma opinião (MALHOTRA, 2012).

Nesta etapa, foram aplicados e validados 240 questionários estruturados com clientes que frequentaram supermercados na região do extremo norte gaúcho. Apenas participaram clientes pós-compra em um período de 30 dias. Antes da sua aplicação, o questionário foi submetido à um pré-teste com 10 entrevistas, envolvendo clientes de supermercados, o que serviu para verificar se o questionário apresentava três importantes elementos: (1) fidedignidade: os resultados serão os mesmos, independentemente de quem o aplicou; (2) validade: os dados coletados são necessários à pesquisa; e (3) operatividade: o vocabulário é acessível e o significado é claro (MARCONI et al., 2008). O qual não apresentou dificuldades em sua aplicação ou interpretação das questões por parte dos respondentes, sendo utilizado como versão final.

Análise dos dados: Os dados coletados através do questionário estruturado foram tabulados em planilha eletrônica e processados por meio de análise estatística descritiva univariada e multivariada (Análise Fatorial Exploratória), mediante software estatístico (SPSS). Os resultados foram apresentados em tabelas, quadros e interpretados a partir de literatura especializada (HAIR JUNIOR et al., 2009), visando atender ao objetivo estabelecido para a pesquisa.

\section{RESULTADOS E DISCUSSÃO}

A amostra é caracterizada por $60 \%$ de homens e $40 \%$ de mulheres, perfazendo o total os 240 casos. A distribuição dos clientes entrevistados por faixa etária envolveu pessoas de 17 a 74 anos de idade, sendo a maioria considerada adulta (79,2\% dos casos), com idade acima dos 30 anos. Em relação à escolaridade dos entrevistados, $41,7 \%$ possui ensino médio incompleto a ensino médio completo, seguido de $37,9 \%$ com ensino fundamental incompleto a ensino fundamental completo, $15,4 \%$ dos respondentes têm ensino superior incompleto a ensino superior completo e, 5\% possui pós-graduação incompleta a pós-graduação completa. Quanto ao estado civil, obteve-se um percentual maior de casados, com 77,9\% dos casos. Do total de entrevistados, $53,4 \%$ possuem um a dois filhos, $25,8 \%$ possuem três ou mais filhos e, $20,8 \%$ não possuem filhos.

A Tabela 3 apresenta os resultados das médias de cada questão, considerando os atributos autodeclarados pelos consumidores a partir da pesquisa exploratória (Questões 1 a 34). A questão 35 que mede a satisfação global e as questões 36,37 e 38 medem a lealdade dos clientes, foram incluídas 
adicionalmente pelos pesquisadores. A satisfação com os atributos foi alta, acima de seis (o máximo da escala é sete). Destaque maior na satisfação com as questões de higiene (18) e de ambiente cheiroso (20). Porém, algumas notas foram piores: Acesso com corrimão (11) e continuar comprando com aumento de preços (37).

Tabela 3: Estatísticas descritivas da escala.

\begin{tabular}{|c|c|c|c|c|}
\hline \multirow{2}{*}{$\begin{array}{l}\text { QUESTÕES } \\
\text { (Variável/Atributo) }\end{array}$} & \multicolumn{4}{|c|}{ ESTATÍSTICAS } \\
\hline & Média & $\begin{array}{l}\text { Desvio } \\
\text { Padrão }\end{array}$ & Mínimo & Máximo \\
\hline 01- Marcas dos produtos & 6,73 & 0,537 & 3 & 7 \\
\hline 02- Produtos de 1 a linha confiáveis & 6,73 & 0,560 & 2 & 7 \\
\hline 03- Qualidade dos produtos & 6,68 & 0,649 & 1 & 7 \\
\hline 04- Produtos diversificados & 6,43 & 0,768 & 3 & 7 \\
\hline 05- Funcionário simpático, agradável, cordial & 6,84 & 0,466 & 3 & 7 \\
\hline 06- Atendimento prestativo & 6,78 & 0,559 & 3 & 7 \\
\hline 07- Funcionários qualificados & 6,70 & 0,714 & 1 & 7 \\
\hline 08- Qualidade geral do atendimento & 6,77 & 0,624 & 3 & 7 \\
\hline 09- Acesso de cadeirantes & 6,35 & 1,071 & 1 & 7 \\
\hline 10- Acesso de idosos & 6,33 & 1,052 & 1 & 7 \\
\hline 11- Acesso com corrimão & 4,55 & 1,946 & 1 & 7 \\
\hline 12- Acesso geral com sinalização & 5,02 & 1,877 & 1 & 7 \\
\hline 13- Variedades de marcas/produtos & 6,56 & 0,700 & 3 & 7 \\
\hline 14- Variedades de carnes e cortes & 6,10 & 1,105 & 2 & 7 \\
\hline 15- Variedades na padaria & 6,32 & 0,956 & 1 & 7 \\
\hline 16- Variedades de frutas/legumes & 6,27 & 0,961 & 1 & 7 \\
\hline 17- Ambiente espaçoso & 6,73 & 0,708 & 3 & 7 \\
\hline 18- Ambiente higienizado e limpo & 6,90 & 0,327 & 5 & 7 \\
\hline 19- Ambiente organizado (gôndolas) & 6,88 & 0,363 & 5 & 7 \\
\hline 20- Ambiente cheiroso & 6,89 & 0,366 & 5 & 7 \\
\hline 21- Espaço do açougue, fruteira e padaria & 6,35 & 1,003 & 2 & 7 \\
\hline 22- Estacionamento amplo e ao $n$ o de vagas & 5,96 & 1,230 & 1 & 7 \\
\hline 23- Estacionamento ser coberto (dia chuva) & 6,73 & 0,507 & 5 & 7 \\
\hline 24- Infraestrutura geral no supermercado & 6,55 & 0,689 & 3 & 7 \\
\hline 25- Localizada no centro da cidade & 5,93 & 1,003 & 2 & 7 \\
\hline 26- Facilidade de acesso ao supermercado & 6,79 & 0,485 & 5 & 7 \\
\hline 27- Localização geral dos supermercados & 6,82 & 0,448 & 5 & 7 \\
\hline 28- Promoções dos produtos e marcas & 6,68 & 0,588 & 4 & 7 \\
\hline 29- Oferta na variedade de produtos & 6,68 & 0,572 & 4 & 7 \\
\hline 30- Promoções semanais & 6,78 & 0,492 & 4 & 7 \\
\hline 31- O que pago proporciona benefício e valor & 6,54 & 0,677 & 5 & 7 \\
\hline 32- Os preços são bons, acessíveis & 6,60 & 0,598 & 5 & 7 \\
\hline 33- Preços são melhores que a concorrência & 6,54 & 0,599 & 5 & 7 \\
\hline 34- Prazos e condições de pagamento & 6,60 & 0,817 & 4 & 7 \\
\hline 35- Avaliação da satisfação global (geral) & 6,74 & 0,578 & 3 & 7 \\
\hline 36- Recompra com redução dos preços & 6,93 & 0,281 & 5 & 7 \\
\hline 37- Recompra com aumento dos preços & 4,39 & 2,189 & 1 & 7 \\
\hline 38- Lembrança, recomendação e fidelidade com a loja & 6,81 & 0,694 & 1 & 7 \\
\hline
\end{tabular}

A satisfação global (35) é a avaliação geral do grau de conformidade do cliente em relação a um produto/serviço, este indicador de satisfação mensura se um produto/serviço atende as necessidades e expectativas dos clientes. No entanto a satisfação global dependerá da expectativa antes da compra e do resultado obtido após o uso (CASTILHO, 2015). A satisfação global com os supermercados considerando a somatória das respostas 6 e 7 (extremos da escala de satisfação), resultou em 95\% de satisfeitos (média de 6,74 pontos), confirmando um resultado positivo com a satisfação global dos serviços no setor supermercadista para a região gaúcha pesquisada.

Já a lealdade é o resultado final da relação entre empresa e o cliente, neste sentido, a lealdade é o desejo que o cliente possui em continuar comprando produtos/serviços da empresa a longo prazo de forma 
repetitiva, recomendando os produtos/serviços da empresa aos amigos (KOSMAN et al., 2014). Na dimensão lealdade dos supermercados foram avaliadas três variáveis: Redução dos preços (36); Aumento dos preços (37) e; Lembrança e recomendação do supermercado (38). Sendo que no geral, para essas três variáveis obteve-se a média 6,04 e o resultado de $80,96 \%$ de afirmações positivas de lealdade com os supermercados.

Cabe destacar que a satisfação do cliente exerce uma importante função na decisão de consumo, pois sua compreensão e mensuração podem ser consideradas como fatores críticos de sucesso para as organizações, tendo em vista que maiores índices de satisfação do cliente tendem a uma maior recompra (LAM et al., 2004). Ou seja, a pesquisa demostrou que clientes satisfeitos com os supermercados também resultam em percentuais de clientes mais leais.

Para identificar os principais fatores de satisfação preconizados pelos consumidores com os serviços de supermercados, utilizou-se a Análise Fatorial Exploratória (AFE) conhecida como uma técnica estatística multivariada que transforma um conjunto de variáveis correlacionadas num conjunto menor de variáveis independentes, combinações lineares das variáveis originais, designadas por "componentes principais". A análise fatorial exploratória analisa o padrão de correlações existentes entre as variáveis e utiliza esses padrões de correlações para agrupar suas variáveis em fatores, os quais são variáveis não-observadas que pretendesse medir a partir das variáveis observadas (HAIR JUNIOR et al., 2009). A análise Fatorial Exploratória permite ao pesquisador obter as principais dimensões para gerar uma teoria ou modelo a partir de um conjunto relativamente grande de construções latentes, representado por um conjunto de itens (WILLIAMS et al., 2010).

Neste trabalho a AFE tem o objetivo de sintetizar as questões em um número de fatores reduzidos de modo a atender ao objetivo inicial deste estudo. Para reduzir estas variáveis em fatores, foi executada uma Análise Fatorial Exploratória (AFE) com o tipo de extração por Análise de Componentes Principais e empregando o método Varimax para a rotação dos fatores. O método de rotação dos fatores Varimax tem o objetivo de obter uma estrutura fatorial na qual uma e apenas uma das variáveis originais esteja fortemente associada com um único fator (componente), e pouco associada aos fatores restantes. A extração realizada pelo método de Componentes Principais foi com base nos autovalores (ou valores próprios) maiores que 1 (um). Na sequência os testes e resultados obtidos com a AFE considerando os 38 itens do questionário.

Teste de KMO e Bartlett para o modelo inicial: O teste de esfericidade (Quadro 1) verifica a hipótese da matriz das correlações ser a matriz identidade. Para a análise de fatores funcionar, é necessário que haja relacionamento entre as variáveis que irão compor a análise fatorial, e se a matriz de correlação é uma matriz identidade, todos os coeficientes de correlação serão zeros. Portanto, busca-se rejeitar a hipótese de que a matriz de correlação é uma matriz identidade. Como valor-p do teste apresentado no quadro é menor que 0,000, rejeitou-se essa hipótese, havendo então correlação entre as variáveis.

Quadro 1: Teste de KMO e Bartlett.

\begin{tabular}{|ll} 
Aprox. Qui-quadrado &, 818 \\
gl & 4343,293 \\
Sig. & 703 \\
&, 000
\end{tabular}


O outro teste apresentado no quadro anterior é o da medida de adequação da amostra Kaiser-MeyerOlkim (KMO). A KMO pode ser calculada para variáveis individuais e múltiplas e representa a razão da correlação ao quadrado para correlação parcial ao quadrado entre as variáveis. A estatística KMO varia entre 0 e 1 . Um valor de 0 indica que a soma de correlações parciais é grande relativa à soma das correlações, indicando difusão no padrão das correlações (portanto, a análise de fatores provavelmente é inadequada). Um valor próximo de 1 indica que padrões de correlação são relativamente compactos, assim, a análise de fatores deveria dar preferência a valores distintos e confiáveis. Valores maiores do que 0,5 são considerados apenas aceitáveis (valores abaixo disso deveriam levar a coletar mais dados ou repensar quais variáveis incluir). Além disso, valores entre 0,5 e 0,7 são medíocres, valores entre 0,7 e 0,8 são bons, valores entre 0,8 e 0,9 são ótimos, e valores acima de 0,9 são excelentes. No caso o valor observado foi 0,818 , considerado um ótimo resultado (HAIR JUNIOR et al., 2009).

Comunalidades do Modelo Inicial: As comunalidades mostram variância total explicada pelos fatores em cada variável. Algumas variáveis apresentaram relação fraca com os fatores retidos (Questões: 13, 22, 23 e 35), pois obtiveram escores abaixo de 0,5. Conforme Hair Junior et al. (2009), indicadores abaixo de 0,5 explicam pouco o construto. Desta forma, as variáveis Q13, Q22, Q23 e Q35 são candidatas a saírem da análise. Estas exclusões provavelmente melhorariam os resultados da AFE.

Variância total explicada pelo modelo inicial: Ao executar a rotação Varimax, não foi possível convergir, não sendo então apresentada na saída (output) do SPSS. Esta saída conteria as cargas fatoriais após a rotação, de modo que cada variável se associe a um fator. Um Modelo Ajustado foi implementado.

Modelo ajustado: A partir deste resultado, buscando-se a melhoria do modelo, levando a realização de uma nova execução da Análise Fatorial Confirmatória, desta vez excluindo-se as questões Q13, Q22, Q23 e Q35 que foram apontadas na análise anterior. Além disso, a Q9, Q24, Q25, Q34, Q37 também foram excluídas, ou por não se firmarem em fatores, ou por se firmarem em vários fatores simultaneamente. Com estas exclusões o modelo melhorou robustamente. Os resultados estão apresentados na sequência.

Comunalidades do modelo ajustado: Com a retirada das questões elencadas no item anterior, verificou-se que nenhuma questão remanescente ficou com cumunalidade abaixo de 0,500 . Conforme Hair Junior et al. (2009), indicadores abaixo de 0,5 explicam pouco do construto.

Teste de KMO e Bartlett para o modelo ajustado: O teste de KMO e o teste de Bartlett continuaram tendo bons resultados (KMO>0,7 e Bartlett com valor $\mathrm{p}<0,05$ ) conforme apresentado no Quadro 2 .

Quadro 2: Teste de KMO e Bartlett do modelo ajustado. Medida Kaiser-Meyer-Olkin de adequação de amostragem.

Teste de esfericidade de Bartlett

\begin{tabular}{|ll} 
Aprox. Qui-quadrado &, 802 \\
gl & 3343,188 \\
Sig. & 406 \\
&, 000
\end{tabular}

Variância total explicada pelo modelo ajustado: A Tabela 4 apresenta os percentuais de variância explicada por cada um dos oito fatores retidos, bem como o percentual de variância explicada conjuntamente por eles, que ficou em $68,479 \%$. 
Tabela 4: Variância total explicada.

\begin{tabular}{|c|c|c|c|c|c|c|c|c|c|}
\hline \multirow{3}{*}{$\begin{array}{l}\text { Componente } \\
\text { (Fatores) }\end{array}$} & \multicolumn{3}{|c|}{ Autovalores iniciais } & \multicolumn{6}{|c|}{$\begin{array}{l}\text { Somas de extração de carregamentos ao Somas de rotação de carregamentos ao } \\
\text { quadrado } \\
\text { quadrado }\end{array}$} \\
\hline & \multirow{2}{*}{ Total } & \multicolumn{2}{|c|}{$\% \quad$ de $\%$} & \multirow{2}{*}{ Total } & \multirow[b]{2}{*}{ \% de variância } & \multirow[b]{2}{*}{$\%$ cumulativa } & \multirow{2}{*}{ Total } & \multirow[b]{2}{*}{ \% de variância } & \multirow[b]{2}{*}{$\%$ cumulativa } \\
\hline & & variância & cumulativa & & & & & & \\
\hline 1 & 6,817 & 23,507 & 23,507 & 6,817 & 23,507 & 23,507 & 3,024 & 10,427 & 10,427 \\
\hline 2 & 3,022 & 10,422 & 33,929 & 3,022 & 10,422 & 33,929 & 2,917 & 10,060 & 20,487 \\
\hline 3 & 2,629 & 9,065 & 42,993 & 2,629 & 9,065 & 42,993 & 2,512 & 8,663 & 29,149 \\
\hline 4 & 1,952 & 6,730 & 49,723 & 1,952 & 6,730 & 49,723 & 2,497 & 8,609 & 37,759 \\
\hline 5 & 1,615 & 5,568 & 55,291 & 1,615 & 5,568 & 55,291 & 2,469 & 8,512 & 46,271 \\
\hline 6 & 1,456 & 5,020 & 60,311 & 1,456 & 5,020 & 60,311 & 2,137 & 7,368 & 53,639 \\
\hline 7 & 1,212 & 4,179 & 64,491 & 1,212 & 4,179 & 64,491 & 2,095 & 7,226 & 60,864 \\
\hline 8 & 1,157 & 3,989 & 68,479 & 1,157 & 3,989 & 68,479 & 1,876 & 6,468 & 67,332 \\
\hline
\end{tabular}

Nota: Método de Extração: Análise de Componente Principal.

Matriz anti-imagem: A matriz anti-imagem indica o poder de explicação dos fatores em cada uma das variáveis analisadas. Os resultados da correlação anti-imagem consideram o MSA (Medidas de Adequação da Amostragem) para cada uma das variáveis analisadas, sendo que valores inferiores a 0,50 são considerados muito pequenos e indicam variáveis que podem ser retiradas da análise. Não foram encontrados valores inferiores a 0,50 na matriz com as variáveis dos fatores.

Correlações reproduzidas e correlações observadas - resíduos: A matriz de correlação reproduzida é uma matriz de dados gerada considerando o modelo como perfeito, considerando uma estimativa dos coeficientes. Para ver se os dados originais estão bons verifica-se a diferença entre a matriz de correlação reproduzida e a matriz dos dados da amostra. Estas diferenças são os resíduos. É desejável que as contagens de resíduos maiores que 0,05 (ou $5 \%$ ) estejam em menos que $50 \%$ dos dados. No caso deste modelo, conforme análises de correlações reproduzidas, cerca de 17,0\% dos resíduos possuem valores absolutos maiores que 0,05, ou seja, está dentro do recomendável (HAIR JUNIOR et al., 2009).

Alpha de Cronbach do modelo ajustado: O coeficiente alfa de Cronbach é uma forma de estimar a confiabilidade de um questionário aplicado em uma pesquisa. Ele mede a correlação entre respostas em um questionário através da análise das respostas dadas pelos respondentes, apresentando uma correlação média entre as perguntas. $O$ coeficiente $\alpha$ é calculado a partir da variância dos itens individuais e da variância da soma dos itens de cada avaliador de todos os itens de um questionário que utilizem a mesma escala de medição. De acordo com Hair Junior et al. (2009), são aceitáveis valores de Alfa de Cronbach acima de 0,700. Os resultados obtidos estão apresentados na Tabela 5.

Tabela 5: Alfa de Cronbach.

\begin{tabular}{lll}
\hline Fatores de satisfação & Alfa de Cronbach & № de Itens \\
\hline Fator 1 &, 868 & 4 \\
Fator 2 &, 799 & 5 \\
Fator 3 &, 891 & 3 \\
Fator 4 &, 755 & 4 \\
Fator 5 &, 823 & 3 \\
Fator 6 &, 756 & 3 \\
Fator 7 &, 761 & 3 \\
Fator 8 &, 889 & 2 \\
Média Geral &, 817 & 27 \\
\hline
\end{tabular}

Todos os fatores obtiveram um Alfa de Cronbach acima 0,700, indicando a confiabilidade dos fatores/construtos. Sendo que na média geral, o resultado do Alfa de Cronbach foi de 0,817, indicando, 
portanto, a confiabilidade da escala referente aos fatores identificados no estudo.

Matriz de componente rotativa do modelo ajustado: A Tabela 6 apresenta a matriz rotacionada dos oito componentes (fatores) extraídos, para o novo modelo. A primeira coluna apresenta o nome do fator teórico identificado, definidos pelos pesquisadores e especialistas a partir da semelhança com os atributos: (1) Atendimento no supermercado com quatro atributos: Funcionário simpático, agradável, cordial e atencioso; Atendimento prestativo; Funcionários qualificados; Qualidade geral do atendimento. (2) Variedades no supermercado com cinco atributos: Espaço do açougue, fruteira e padaria; Espaço amplo/variado; Variedades de frutas/legumes; Variedades na padaria; Variedades de carnes e cortes. (3) Promoções no supermercado com três atributos: Oferta na variedade de produtos; Promoções dos produtos e marcas nas gôndolas; Promoções semanais. (4) Produtos no supermercado com quatro atributos: Qualidade dos produtos; Produtos de primeira linha confiáveis; Marcas dos produtos; Produtos diversificados. (5) Ambiente do supermercado com três atributos: Higienizado e limpo; Organizado (gôndolas); Ambiente cheiroso. (6) Preços do supermercado com três atributos: Os preços são bons, acessíveis, adequados; Os preços são melhores que dos concorrentes; O que pago me proporciona benefício e valor. (7) Acessibilidade ao supermercado com três atributos: Acesso com corrimão; Acesso geral com sinalização; Acesso de idosos. (8) Localização do supermercado com dois atributos: Facilidade de acesso ao supermercado; Localização geral dos supermercados.

Tabela 6: Matriz de componente rotativa ${ }^{a}$

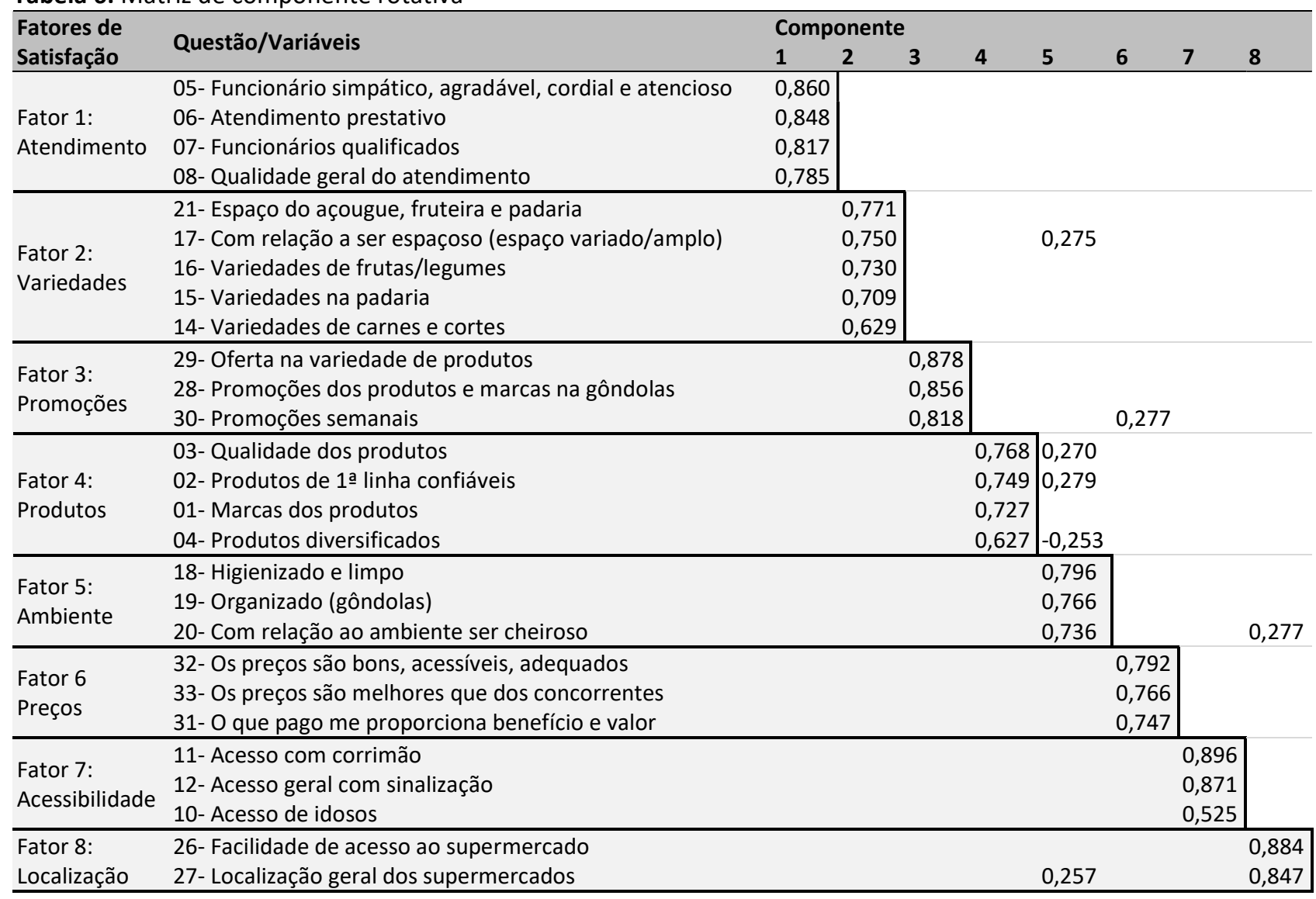

Nota: Método de Extração: Análise de Componente Principal. Método de Rotação: Varimax com Normalização de Kaiser. a. Rotação convergida em 7 iterações.

Portanto, são estes os fatores que mais se destacaram como relevantes para satisfação dos clientes 
de supermercados da pesquisa. A satisfação resulta de um processo de comparação entre expectativas e desempenho de atributos inerentes ao serviço. Também resulta da experiência emocional dos consumidores ao se sentirem bem consigo ao apreciar alguma experiência (KUNZ et al., 2011). É importante conhecer os fatores de satisfação preconizados pelos consumidores aos supermercados para estabelecer a melhor estratégia no negócio, sem com isso negligenciar os fatores externos que também impactam os supermercados. $\mathrm{O}$ aprimoramento na qualidade dos atributos de cada um dos fatores identificados por essa pesquisa tenderá a uma maior satisfação e bem-estar social por parte dos consumidores, proporcionando maior valor ao cliente e maior valor ao supermercado em forma de recompra e fidelização da clientela.

\section{CONCLUSÕES}

Os supermercados devem promover a satisfação da sua clientela a partir de produtos e serviços que atendam às necessidades e os desejos do seu público-alvo, ofertando serviços e produtos de valor. Este entendimento sobre o que é valor para o cliente permitirá em última análise a sua satisfação e o aumento do desempenho do supermercado (CHAMIE et al., 2015). No entanto, a compreensão dos fatores que promovem valor e satisfação ao cliente não é totalmente compreensível, o que objetivou a realização deste estudo o de identificar os principais fatores de satisfação preconizado por consumidores em serviços de supermercados, cujas pesquisas e publicações no país ainda são incipientes.

Os resultados obtidos a partir da análise fatorial permitiram a identificação de oito fatores: Produtos; Atendimento; Acessibilidade; Variedades; Ambiente; Localizações; Promoções e Preços dos Supermercados. Com um Alfa de Cronbach médio de 0,8 para a escala, o que indica estatisticamente uma boa confiabilidade e aprovação nos resultados obtidos (HAIR JUNIOR et al., 2009), sendo, portanto, a escala uma das contribuições acadêmicas do estudo, além da identificação de variáveis primárias (atributos). Os fatores identificados formam as dimensões pelas quais os clientes satisfazem suas necessidades ao frequentar os supermercados. A qualidade do serviço no varejo supermercadista é essencial para satisfazer os clientes, retendo-os e criando lealdade entre a clientela (NAIK et al., 2010). Portanto, os resultados obtidos proporcionam informações de implicações para a gestão mercadológica dos supermercados e amplia a compreensão científica e acadêmica dos fatores e suas variáveis (atributos) de satisfação preconizados pelos consumidores no segmento supermercadista, tendo em vista que os trabalhos publicados em periódicos científicos abordam muito mais a qualidade dos serviços do que propriamente a satisfação dos consumidores com supermercados (KONČAR et al., 2015; CLARKE et al., 2012; GALLON et al., 2008).

Os fatores identificados, juntamente com suas variáveis, são responsáveis pela promoção da satisfação dos consumidores com supermercados, são promotores de valor para clientela e de captura de valor aos supermercados, sobretudo por meio de benefício para o bem-estar social da população que reside nos municípios onde o estudo foi desenvolvido, bem como uma contrapartida de valor para o supermercadista em sua imagem comercial e geração de receita financeira, pois a satisfação do cliente tem um impacto positivo na rentabilidade das empresas, considerando que clientes satisfeitos tendem a recompra (ANGELOVA et al., 2011). A satisfação do cliente também influencia nas vendas e nos lucros a longo 
prazo (AL-ALI et al., 2015).

O estudo teve algumas limitações e dificuldades que serão compartilhadas. Na coleta dos dados, ressalta-se o deslocamento entre cidades distantes para aplicação dos questionários, que apesar do esforço em abranger o maior número possível de cidades na região do extremo norte gaúcho, não permite conclusões definitivas acerca de todas cidades e unidades de supermercados existentes na região a partir dos resultados apresentados, muito menos generalizações para outras partes do estado do Rio Grande do Sul e do Brasil. Todavia, em decorrência dos poucos estudos e publicações acerca do tema no país, este trabalho proporciona uma singela contribuição acadêmica e mercadológica na compreensão do problema inicial da pesquisa em identificar os fatores que promovem satisfação em serviços de supermercados.

Para pesquisas e trabalhos futuros relacionados ao tema da satisfação do consumidor com supermercados ou serviços correlacionados ao autosserviço, sugere-se que os resultados com os fatores que impactam diretamente na satisfação dos serviços em supermercados, identificados por este estudo, sejam utilizados como referência e base de comparação para estudos e pesquisas futuras. Destaca-se ainda, a necessidade de um estudo mais abrangente no país em relação a influência da cultura e dos valores pessoais, bem como das características regionalistas na formação dos fatores determinantes para satisfação com autosserviço em supermercados. Outro aspecto a ser pesquisado é o efeito das ações de melhoria de gestão mercadológica a priori, para redução e neutralização dos fatores de maior insatisfação no resultado a posteriori de reavaliação da satisfação com a qualidade dos serviços prestados pelos supermercados.

\section{REFERÊNCIAS}

AL-ALI, M.; BAZEN, N. E. N.; SHAMSUDDIN, S. M.. Key Determinants of customer satisfaction: evidence from Malaysia grocery stores. Journal of Theoretical and Applical Information Technology, v.74, n.3, p.286-299, 2015.

ANGELOVA, B.; ZEKIRI, J.. Measuring customer satisfaction with service quality using american customer satisfaction model (ACSI Model). International Journal of Academic Resear in Business and Social Sciences, v.1, n.3, p.22226990, 2011. DOI: https://doi.org/10.6007/ijarbss.v1i2.35

ASCAR, A. C.. Da mercearia aos primeiros supermercados. Revista da Associação Brasileira de Supermercados Superhiper, v.44, n.498, p.58-63, 2018.

BRASIL. Lei n.5.991, de 17 de dezembro de 1973. Brasília: DOU, 1973.

CASTILHO, R.. Customer behavior and factores that effect satisfaction and risk pesrfection of purchases of own brand food products. Revista de Administração e Inovação, v.12, n.1, p.353-379, 2015.

CHAMIE, B. C.; IKEDA, A. A.. O valor para o cliente no varejo. Brazilian Business Review, v.12, n.2, p.49-69, 2015. DOI: http://dx.doi.org/10.15728/bbr.2015.12.2.3

CHERNEV, A.; HAMILTON, R.; GAL, D.. Competing for consumer identity: limits to self-expression and the perils of lifestyle branding. Journal of Marketing, v.75, n.3, p.66-82, 2011. DOI: https://doi.org/10.1509/jmkg.75.3.66
CLARKE, I.; KERKUP, M.; OPPEWAL, H.. Consumer satisfaction with local retail diversity in the UK: effects of supermarket access, brand variety, and social deprivation. Environment and Planing, v.44, n.8, p.1896-1911, 2012. DOI: https://doi.org/10.1068/a44310

COOPER, D. R.; SCHINDLER, P. S.. Métodos de pesquisa em administração. 10 ed. Porto Alegre: Bookman, 2011.

CZEPIEL, J. A.; ROSENBERG, L. J.; AKERELE, J.. Perspectives on consumer satisfaction AMA Educators. Proceedings Chicago, v.44, n.1, p.55-66, 1974

DAY, R. L.. Modeling choices among alternative responses to dissatisfaction. Advances in Consumer Research, v.11, n.1, p.469-499, 1984.

ENDERS, W. T.; MENDES, N.; HESKETH, J.. A pesquisa da percepção individual aplicada as áreas de administração e planejamento: conceitos, teorias e metodologia. Revista de Administração, v.18, n.1, p.23-31, 1983.

GALLON, A. V.; SILVA, T. P.; HEIN, N.; OLINQUEVITCH, J. L.. Avaliação da Importância dos Atributos e a Satisfação dos Clientes de Supermercados do Médi Vale do Itajaí - SC. Revista Brasileira de Gestão de Negócio RBGN, v.10, n.27, p.150-160, 2008. DOI:

https://doi.org/10.7819/rbgn.v10i27.280

HAIR JUNIOR, J. F.; HULT, G. T. M.; RINGLE, C.. A primer on 
partial least squares structural equation modeling (PLSSEM). Thousand Oaks: Sage, 2014.

HAIR JUNIOR, J. F.; HULT, G. T. M.; RINGLE, C.. Análise multivariada de dados. 6 ed. Porto Alegre: Bookman, 2009.

HANSEMARK, O. C.; ALBINSON, M.. Customer satisfaction and retention: the experiences of individual employees. Journal of Theory and Practice, v.14, n.1, p.40-57, 2004. DOI: https://doi.org/10.1108/09604520410513668

JIN, N. P.; LEE, S.; HUFFMAN, L.. Impact of restaurant experience on brand image and customer loyalty. Moderating Role of Dining Motivation, v.29, n.6, p.532-551, 2012.

JONES, M. A.; SUH, J.. Transaction-specific satisfaction and overall satisfaction: an empirical analysis. Journal of Services Marketing, v.14, n.2, p.147-159, 2000. DOI:

https://doi.org/10.1108/08876040010371555

KHAN, M. M.; FASIH, M.. Impact of service quality on customer satisfaction and customer loyalty: evidence from banking sector. Pakistan Journal of Commerce and Social Sciences, v.8, n.2, p.331- 354, 2004.

KONČAR, J.; MARIĆ, R. M.. Job satisfaction in trade sector: Evidence from the retailers in the largest supermarkets of the Western Balkans. Revija za Socijalnu Politiku, v.22, n.3, p.375-392, 2015. DOI:

https://doi.org/10.3935/rsp.v22i3.1268

KOSMAN, N. B.; PERMARUPAN, P. Y.; MAMUN, A. A.; ZAINOL, N. R. B.. Examining the association between consumer satisfaction, complain handling and loyalty programs with consumer loyalty towards hypermarket in Batu Pahat, Johor, Malaysia. International Business and Management, v.8, n.1, p.15-19, 2014.

KOTLER, P.; KELLER, K. L.. Administração de Marketing. 14 ed. São Paulo: Pearson Education do Brasil, 2012.

KUMARADEEPAN, V.; PATHIMINI, M. G. S.. Customer satisfaction and customer loyalty: leading super markets in Jaffna district, Sri Lanka. Business Management and Strategy, v.8, n.2, p.67-76, 2017. DOI: https://doi.org/10.5296/bms.v8i2.12159

KUNZ, W.; SCHMITT, B.; MEYER, A.. How does perceived firm innovativeness affect the consumer?. Journal of Business Research, v.64, n.8, p.816-822, 2011. DOI: https://doi.org/10.1016/i.jbusres.2010.10.005

LAM, S. Y.; SHANKAR, V.; ERRAMILLI, M. K.; MURTHY, B.. Customer value, satisfaction, loyalty, and switching costs: an illustration from a business-to-business service context. Journal of the Academy of Marketing Science, v.32, n.3, p.293-311, 2004. DOI:

https://doi.org/10.1177/0092070304263330

LEMON, K. N.; VERHOEF, P. C.. Understanding customer experience throughout the customer journey. Journal of Marketing, v.80, n.6, p.69-96, 2016. DOI: https://doi.org/10.1509/im.15.0420

MANTOVANI, D.; KORELO, J. C.; PRADO, P. H. M.; SANTOS, T. S.. Emotional suppression as a moderator of the impact of transgression on consumers' satisfaction. REMark - Revista Brasileira de Marketing, v.12, n.4, p.27-43, 2013. DOI: https://doi.org/10.5585/remark.v12i4.2537

MAHFOOZ, Y.. Relationship between service quality and customer satisfaction in hypermarkets of Saudi Arabia. International Journal of Marketing Studies, v.6, n.4, p.1022, 2014. DOI: https://doi.org/10.5539/ijms.v6n4p10

MALHOTRA, N. K.. Pesquisa de marketing: uma orientação aplicada. Porto Alegre: Bookman, 2012.

MARCONI, M. A.; LAKATOS, E. M.. Técnicas de pesquisa. 7 ed. São Paulo: Atlas, 2008.

MUNIZ, K. M.; SILVA, W. V.; MAFFEZZOLLI, E. C. F.. Proposta de um modelo de mensuração da satisfação do consumidor de festas e baladas. Brazilian Journal of Marketing, v.13, n.1, p.93-105, 2014. DOI:

https://doi.org/10.5585/remark.v13i1.2510

NAIK, C. N. K.; GANTASALA, S. B.; PRABHAKAR, G. V.. Service quality (Servqual) and its effect on customer satisfaction in retailing. European Journal of Social Sciences, v.16, n.2, p.231-243, 2010.

NEUBUSER, M. E.; ZAMBERLAN, L.; SPAREMBERGER, A.. A satisfação do consumidor de supermercados. Revista de Administração, v.3, n.4, p.1-13, 2004.

OLIVEIRA, V. M.; CÂNDIDO, G. A.. As contribuições dos conceitos e modelos de redes organizacionais no setor varejista: um estudo exploratório em pequenos supermercados no Estado da Paraíba. Revista Eletrônica de Administração, v.15, n.3, p.702-728, 2009.

PAPPU, R.; QUESTER, P.. Does customer satisfaction lead to improved brand equity? an empirical examination of two categories of retail brands. Journal of Produc. Brand Management, v.15, n.1, p.4-14, 2006. DOI: https://doi.org/10.1108/10610420610650837

PIZAM, A.; ELLIS, T.. Customer satisfaction and its measurement in hospitality enterprises. International Journal of Contemporary Hospitality Management, v.11, n.7, p.326-339, 1999. DOI: https://doi.org/10.1108/09596119910293231

PRIDE, W. M.; FERRELL, O. C.. Marketing. Mason: SouthWesthern Cengage Learning, 2010.

REIANU, D. G.. Analysis of customer satisfaction in case of the day center for the Elderly, Cluj-Napoca city hall. Transylvanian Review of Administrative Sciences, v.10, n.41, p.170-189, 2014

SALLAM, M. A.. An investigation of corporate image effect on wom: the role of customer satisfaction on trust. International Journal of Business Administration, v.7, n.3, p.27-35, 2016. DOI: https://doi.org/10.5430/ijba.v7n3p27

SHARMA, R. B.. Customers satisfaction in telecom sector in Saudi Arabia: an empirical investigation. European Scientific Journal, v.10, n.13, p.354-363, 2014. DOI: https://doi.org/10.19044/esj.2014.v10n13p\%25p

SILVEIRA, J. A.; LEPSCH, S. L.. Alterações recentes na 
economia do setor supermercadista brasileiro. Revista de Administração, v.32, n.2, p.5-13,1997.

STEENEKEN, F.; ACKLEY, D.. A Complete model of the supermarket business. 2012.

WILLIAMS, B.; OSMAN, A.; BROWN, T.. Exploratory factor analysis: a five-step guide for novices. Australasian Journal of Paramedicine, v.8, n.3, p.1-13, 2010. DOI:

https://doi.org/10.33151/ajp.8.3.93

YEVDOKYMENKO, N.. Antecedentes e consequências de orientação para o mercado. Dissertação (Mestrado em Administração) - Universidade Autónoma de Lisboa, Lisboa, 2013.

A CBPC - Companhia Brasileira de Produção Científica (CNPJ: 11.221.422/0001-03) detém os direitos materiais desta publicação. Os direitos referem-se à publicação do trabalho em qualquer parte do mundo, incluindo os direitos às renovações, expansões e disseminações da contribuição, bem como outros direitos subsidiários. Todos os trabalhos publicados eletronicamente poderão posteriormente ser publicados em coletâneas impressas sob coordenação da Sustenere Publishing, da Companhia Brasileira de Produção Científica e seus parceiros autorizados. Os (as) autores (as) preservam os direitos autorais, mas não têm permissão para a publicação da contribuição em outro meio, impresso ou digital, em português ou em tradução. 